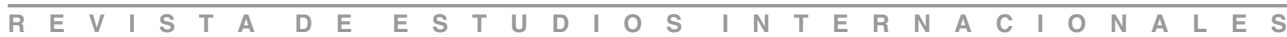

\title{
El mundo en el año 2050
}

Francisco Orrego Vicuña*

\section{Documento}

El rumor que circulaba insistentemente ha sido confirmado: se ha establecido contacto con seres extraterrestres, no sólo una vez sino que ya en dos oportunidades. La vida inteligente existe más allá de este planeta. Mayor inquietud ha causado quizás el hecho de que se ha encontrado en la cordillera de los Andes un instrumento avanzado para medir las características de nuestra atmósfera. Muchos son los que piensan que éste es un paso preparatorio para una primera visita la tierra. Si acaso será ésta pacífica o de otra naturaleza está todavía por verse.

Los pilares de la sociedad internacional se han visto estremecidos por este acontecimiento. En verdad, él no era enteramente inesperado, sólo que nadie había pensado que pudiese ocurrir tan pronto. El primer impacto puede apreciarse en la vida religiosa y

${ }^{*}$ El autor es Miembro de Número de la Academia Chilena de Ciencias Sociales, Políticas y Morales del Instituto de Chile y fue honrado con el Premio Nacional de Humanidades y Ciencias Sociales en 2001. Este ensayo fue escrito para un concurso internacional convocado por The Economist y Shell en 2000 y se publica ahora por primera vez en castellano, con ligeras adaptaciones editoriales. 
El mundo

en el año 2050

espiritual. Es un hecho que ella ha venido avanzando en el curso de la primera mitad del siglo veintiuno y al menos se ha alcanzado el carácter ecuménico del Cristianismo mediante la unificación de sus principales iglesias. El Islam y el Budismo no han estado tampoco ausentes de esta convergencia. Más importante aún es el hecho de que el resurgimiento religioso en China ha significado que en ninguna parte del mundo exista hoy día una sociedad oficialmente atea. Otra cosa es por cierto que el mundo esté efectivamente viviendo de acuerdo a esa religiosidad.

La situación alcanza ahora una gran complejidad. Para algunos es el regreso del Mesías, o su llegada. Es sí interesante anotar que las señales que llegan de más allá de nuestra tierra contienen elementos claramente identificados del Arameo y del Hebreo Antiguo. Para otros se trata de una civilización que tomará contacto con la religión quizás por primera vez. El Vaticano ha llamado a realizar un diálogo ordenado, comenzando por los dirigentes espirituales del mundo y siguiendo con quienes puedan llegar del espacio. Este enfoque debe ser desde luego bienvenido. Lo que debe claramente evitarse es una reacción histérica que sólo podría contribuir a hacer las cosas más graves, no faltando por cierto los profetas de la catástrofe que encuentran en estas noticias buen caldo de cultivo.

Desde un punto de vista político, el impacto de estos acontecimientos es difícil de prever, pero no debe pensarse que necesariamente deberá ser negativo. Después del intento de China de alcanzar el poder mundial el año 2010, que encontró amplio apoyo en muchos sectores políticos debido a su desilusión con los dirigentes occidentales de la época, la sociedad internacional ha evolucionado hacia nuevas formas de entendimiento. Las cuatro federaciones que actualmente existen han sido organizadas en función de las necesidades de la cooperación y han tenido éxito en preservar la identidad nacional y cultural de las unidades que las integran. Francia es siempre Francia, como Indonesia es todavía Indonesia. Tampoco responden estas federaciones a los criterios cerrados del pasado, a veces fundamentados en la identificación racial, como era el caso de Norteamérica, Europa Occidental y Rusia, entre otros. Hoy día se conciben en una escala mayor de acuerdo a las realidades geográficas y económicas. La Federación Pan-Pacífico, la Federación Euro-Mediterránea, la Coalición Afro-Asiática y el Entendimiento de las Américas reflejan estas nuevas realidades. 
La Carta Mundial adoptada luego de los acontecimientos de 2010 demostró ser un paso adecuado. El consejo de Gobierno ha funcionado sin tropiezos en este marco político de mayor simplicidad. En cooperación con la Asamblea Legislativa Consultiva ha podido proponer las medidas necesarias para asegurar la marcha expedita de los asuntos internacionales. Si bien estas medidas deben ser aprobadas por las Federaciones, ello no ha encontrado mayor dificultad al tener todas idéntica representación en esos órganos. Una Corte Constitucional Mundial ha podido resolver las controversias entre las federaciones o sus unidades, a la vez que un vasto sistema de jurisdicciones especializadas ha podido satisfacer la solución de controversias en materia de inversiones, comercio, derechos individuales y otros asuntos. Individuos y empresas tienen acceso expedito a sistemas alternativos de solución de controversias.

Si acaso el desafío extraterrestre es de carácter pacífico, la actual organización de la cooperación mundial debería ser más que suficiente para manejarlo, pues se apoya en el consenso y la armonización de intereses divergentes. Si acaso no tuviera carácter pacífico, los problemas de preparación militar, recursos y tecnología ocuparán un lugar central. Las federaciones están bien equipadas en este plano, al menos de acuerdo a los criterios terrestres. Si bien no ha habido guerras mayores desde las confrontaciones de 2010 y sólo han persistido conflictos internos o regionales de carácter limitado, ha habido suficiente experiencia con tropas profesionales, unidades de desplazamiento rápido, armas guiadas y escenarios de guerra virtual. Las armas nucleares son hoy día parte del pasado y de hecho han sido eliminadas, pues los rayos de fisión permiten destruir cualquier blanco sin efectos masivos o implicaciones ambientales. La práctica de la intervención preventiva con fines humanitarios también ha sido abandonada, pues muchas veces conducía a más abuso que ayuda. Desde luego que no sería aconsejable recurrir a medidas de ataque preventivo en las actuales circunstancias pues no existe indicación alguna de intenciones agresivas por los potenciales visitantes. Tan sólo es necesario evitar con cuidado que puedan revivir las guerras religiosas en la tierra.

La economía que tenemos en 2050 está en un estado satisfactorio y permite atender las necesidades básicas de las federaciones. Sin embargo, ella es tan diferente de la que conoció el mundo 
El mundo

en el año 2050

a comienzos de siglo. Hoy día es una economía enteramente privatizada y los gobiernos locales o federales ya no interfieren en las decisiones de los empresarios e individuos, salvo en la medida exigida por la libertad de competencia, la solución de controversias y la tributación. Las empresas grandes y pequeñas tienen los mismos derechos y oportunidades, lo que exige examinar las fusiones con especial atención para evitar toda forma de posición dominante. Las aduanas ya no existen; el mundo es un solo mercado donde quien lo desee puede comprar o vender. Los subsidios no son ahora autorizados. Formas de autorregulación aseguran que las empresas y negocios se manejen de manera responsable. Las transacciones electrónicas han simplificado las operaciones de los mercados financieros y del comercio, hasta el punto de que hoy existe una sola bolsa mundial, ubicada en Singapur.

Las federaciones han llevado a cabo una política común para atender a las necesidades de los pobres y quienes se encuentran en desventaja económica. Es cierto que hay siempre pobres y ricos, pero esa política ha sido tan exitosa que puede sostenerse que finalmente la extrema pobreza ha sido derrotada. En parte, el enfoque descansa en sistemas privados de seguridad social que proveen ayuda transitoria, como también en parte se apoya en un esfuerzo sostenido para capacitar y habilitar financieramente a los individuos, familias y comunidades de tal manera que puedan emprender sus propias actividades económicas.

La mayoría de las organizaciones internacionales del pasado han sido desmanteladas debido a la creciente ineficacia que las caracterizaba. El Fondo Mundial se preocupa de administrar la moneda única, en tanto que el Banco para el Desarrollo asegura la capacitación y facilidades de financiamiento necesarias para el desarrollo privado. Unas pocas entidades de coordinación administran los problemas de interés común para las federaciones.

La prosperidad económica que conocemos hoy es también el resultado de la disponibilidad de recursos naturales y tecnología. Las preocupaciones del pasado acerca de la escasez de energía han sido ya superadas hace algún tiempo. Ello se debió primero al descubrimiento de gigantescos yacimientos de petróleo en la Antártica, que pudieron ser pronto explotados con tecnologías ambientales seguras; se debió enseguida al desarrollo de la tecnología para aprovechar la energía solar en gran escala; y, en especial, al descubrimiento de nuevas formas de energía. El más tras- 
cendental de estos descubrimientos ha sido el de la conversión química del agua del mar en energía a un bajo costo. Hoy día también se extraen regularmente los recursos minerales de los fondos marinos.

La agricultura y la producción de alimentos es también abundante y la población mundial tiene una adecuada nutrición. Los océanos están eficientemente administrados en el marco de un sistema de derechos privados y cuotas individuales transferibles para su explotación. Las preocupaciones acerca de un exceso de población y el colapso del mundo también son parte del pasado pues demostraron carecer de fundamento. La vida es hoy día protegida, no restringida. Un factor influyente en este cambio de política fue que el envejecimiento de la población de Europa, América del Norte y Japón no permitía ya sostener el crecimiento económico y los costos de la seguridad social, lo que a su vez indujo a un creciente flujo de inmigrantes de las regiones vecinas. El problema alcanzó recientemente una solución mediante la ampliación de las federaciones, la expansión de la prosperidad económica y el compartir la riqueza y la fuerza de trabajo.

La vida en la sociedad internacional también ha cambiado significativamente al entrar a la segunda mitad del siglo. Las comunicaciones y la información son instantáneas. La red mundial de voz e imagen permite a toda persona hablar a cualquier otra persona, o verla en imagen, con sólo presionar una tecla de su aparato móvil. Más aún, el servicio básico es gratuito. La información también está disponible en consola de noticias, donde se puede leer e imprimir cualquier noticia de interés general, o donde se puede suscribir a cualquier fuente por una cantidad nominal.

Como consecuencia del desarrollo de las comunicaciones los viajes se han hecho menos frecuentes como manera de realizar negocios o de asistir al trabajo. Las empresas y las industrias se han automatizado y la mayoría de los trabajadores y empleados pueden realizar sus tareas en sus casas mediante sistemas entrelazados. El transporte, sin embargo, se ha desarrollado en el ámbito de la recreación y el comercio. Los problemas de tránsito ya son un problema del pasado. Al entrar a una ciudad se puede indicar el punto de destino en su orientador y el vehículo será electrónicamente guiado hasta allí siguiendo la ruta más adecuada. El transporte masivo en áreas urbanas es todo subterráneo. El 
El mundo

en el año 2050

transporte aéreo es principalmente suborbital permitiendo viajar entre las ciudades más distantes del mundo en no más de cuatro horas. Salvo en las rutas de más tráfico, las aeronaves son hoy más pequeñas, no más grandes. Los derechos de los pasajeros están claramente establecidos y se hacen valer estrictamente. También hay excursiones disponibles por aviones misiles a planetas cercanos, pero ellas no han resultado tan populares debido a las muchas maravillas que ofrece el mundo.

El transporte aéreo se utiliza hoy día principalmente para largas distancias pues hay otros medios más apropiados para las distancias cortas y medianas. Cabe destacar en particular el tren supersónico que atraviesa los continentes a la velocidad del sonido, o el ultra carguero que atraviesa los mares en pocos días. El transporte de mercaderías es hoy enteramente automatizado. Ya no se necesitan pasaportes pues no hay controles de inmigración y cualquier persona pueda ser ubicada electrónicamente al instante. Tampoco existen ya las embajadas.

El impacto de las comunicaciones puede también apreciarse en la educación. Los alumnos ya no necesitan asistir cada día a las escuelas, sino que lo hacen con una periodicidad preestablecida, pues casi todo el trabajo se realiza mediante redes electrónicas. Las universidades ofrecen títulos avanzados de la misma forma. Todos los textos de estudio están disponibles electrónicamente. Nadie está hoy impedido de alcanzar la educación, cualquiera sea su edad o lugar de residencia. El mundo, como en el Renacimiento, ha vuelto a ser un lugar de enseñanza. El idioma tampoco es hoy un obstáculo. La educación también ha eliminado completamente la discriminación basada en consideraciones de raza, género, nacionalidad o creencia política o religiosa. La función pública es accesible a todo dirigente competente. La vida en familia ha resurgido fuertemente, siendo ésta una de las contribuciones más positivas de las culturas que solían conocerse como el mundo en desarrollo.

La calidad de la vida y de la salud han llegado a su mayor desarrollo en 2050. Nuevas tecnologías para la energía y la producción, como nuevos vehículos de transporte, han eliminado los problemas ambientales. Hoy sólo se emiten vapores de agua. La medicina ha erradicado las epidemias y enfermedades sociales. El cáncer y los ataques cardíacos son hoy eventos excepcionales. El código genético y el funcionamiento del cerebro son hoy día 
conocidos en su integridad. Como resultado de todo ello, las expectativas de vida han aumentado de manera dramática.

La pregunta que subsiste, sin embargo, es si acaso este mundo tan cambiado es realmente feliz. En un mundo de comunicaciones instantáneas el peligro del "Hermano Mayor" está siempre presente, hasta el punto de que crecientemente ocurren violaciones de la vida privada. Nuevas tecnologías han sido desarrolladas para impedir este peligro y el sistema de control y protección judicial ha funcionado bien hasta ahora. La democracia electrónica es una realidad. Periódicamente se realizan consultas a la ciudadanía mediante la red política. Aún cuando las ideologías no tienen hoy día tanta influencia como en el pasado y los aspectos prácticos y técnicos ocupan un lugar prominente en la adopcón de decisiones, la política siempre involucra diferentes visiones de la sociedad. Los intentos de dominación política de 2010 todavía se recuerdan en forma clara.

También han surgido peligros nuevos para la sociedad. El más serio de ellos es que al avanzar la tecnología de la clonación de muchas especies para el beneficio de la ciencia, la medicina y la industria, el impedir la clonación humana ha resultado un objetivo difícil. En tanto que las políticas públicas en este plano están bien concebidas, existe siempre el riesgo de una actividad clandestina. La utilización de robots y de la inteligencia artificial ha sido ampliamente desarrollada, pero ninguna de estas tecnologías se ha acercado ni se acercará al pensamiento humano

El bienestar material no es un sustituto de la dimensión espiritual y moral de los individuos y la sociedad, elemento que en ocasiones es el que pareciera faltarle al mundo. Junto al progreso que se observa hay también un sentido de vanidad y arrogancia que se acentúa en la medida que la vida se hace más fácil y abundante. El considerarse superior, creer que el hombre puede conquistar la vida y la muerte, o simplemente pensar que nada hay por sobre el hombre, son algunas de las manifestaciones de este fenómeno.

Quizás los visitantes del más allá puedan ayudar a la humanidad a incorporar esta otra dimensión. En este sentido, por mucho que pueda ser el temor o la incertidumbre que esta visita suscite, sería lamentable que ella no se materializara. Para entenderse a sí mismo el mundo quizás necesita aprender de quienes vienen a entendernos. 